\title{
Catalytic activity of maghemite supported palladium catalyst in nitrobenzene hydrogenation
}

\author{
Viktória Hajdu · Ádám Prekob ${ }^{1}$ Gábor Muránszky ${ }^{1}$ István Kocserha² \\ Zoltán Kónya $^{3}$ - Béla Fiser ${ }^{1,4} \cdot$ Béla Viskolcz ${ }^{1}$. László Vanyorek ${ }^{1}$ (D)
}

Received: 29 October 2019 / Accepted: 31 December 2019 / Published online: 9 January 2020

(c) The Author(s) 2020

\begin{abstract}
A maghemite supported palladium catalyst was prepared and tested in nitrobenzene hydrogenation. The catalyst support was made by a newly developed combined technique, where sonochemical treatment and combustion have been used. As a first step, maghemite nanoparticles were synthesized. Iron(II) citrate was treated in polyethylene glycol by high-intensity ultrasound cavitation to get a homogeneous dispersion, then the product was combusted. The produced powder contained maghemite nanoparticles with $21.8 \mathrm{~nm}$ average particle size. In the second step of catalyst preparation, the magnetic nanoparticles were dispersed in the ethanolic solution of palladium(II) nitrate. The necessary energy for the reduction of $\mathrm{Pd}^{2+}$ ions was achieved in the "hot spots" by acoustic cavitation, thus catalytically active palladium was formed. The prepared maghemite supported Pd catalyst have been tested in nitrobenzene hydrogenation at three different temperatures $(283 \mathrm{~K}, 293 \mathrm{~K}$ and $303 \mathrm{~K}$ ) and constant pressure (20 bar). At $293 \mathrm{~K}$ and $303 \mathrm{~K}$, the conversion and selectivity of nitrobenzene was above $99 \%$ and $96 \%$, respectively. However, the selectivity was only $73 \%$ at $273 \mathrm{~K}$ because the intermediate species (azoxybenzene and nitrosobenzene) have not been transformed to aniline. All in all, the prepared catalyst is successfully applied in nitrobenzene hydrogenation and easily separable from the reaction media.
\end{abstract}

Keywords Magnetic catalyst $\cdot$ Selectivity $\cdot$ Nitrobenzene $\cdot$ Aniline

\section{Introduction}

Several different complex catalysts have been successfully applied in the hydrogenation of nitro groups, such as carbon $(\mathrm{C})$, silica $\left(\mathrm{SiO}_{2}\right)$ or alumina $\left(\mathrm{Al}_{2} \mathrm{O}_{3}\right)$ supported $\mathrm{Pd}, \mathrm{Pt}, \mathrm{Ru}, \mathrm{Rh}, \mathrm{Ni}, \mathrm{Fe}$ or bimetallic systems [1-13]. The easy handling and

László Vanyorek

kemviki@uni-miskolc.hu

Extended author information available on the last page of the article 
separability are very important properties for the catalysts. These can be improved by introducing magnetic features (e.g. magnetic catalyst supports), which will allow the easy and efficient removal of the catalysts after the reactions. For this reason, magnetic systems have been widely used in various applications. Magnetite $\left(\mathrm{Fe}_{3} \mathrm{O}_{4}\right)$ / silica composite catalyst was used for esterification of palmitic acid with methanol [14]. $\mathrm{Pd}, \mathrm{Pr}-\mathrm{Cu}$ and $\mathrm{Pr}_{6} \mathrm{O}_{11}$ decorated $\mathrm{Fe}_{3} \mathrm{O}_{4} / \mathrm{SiO}_{2}$ catalyzed the reduction of 2,4-dinitrophenylhydrazine, 4-nitrophenol and chromium(VI) ions, Mizoroki-Heck coupling reaction, and the catalytic ozonation of acetochlor [15-17]. Magnetite/ carbon support was applied in Suzuki-Miyaura cross-coupling of 4-iodotoluene and phenylboronic acid and aniline synthesis by palladium [18, 19]. By magnetite/ alumina supported $\mathrm{Pd}$ catalyst the hydrogenation of nitrate in water and 4-nitrophenol can be achieved [20,21]. Magnetic iron oxides can be combined with different layered double hydroxides $\left(\mathrm{Fe}_{3} \mathrm{O}_{4}-\mathrm{LDH}\right)$, complex magnesium silicates $\left(\mathrm{Fe}_{3} \mathrm{O}_{4}\right.$-sepiolite $)$ and hydroxyapatite $\left(\gamma-\mathrm{Fe}_{2} \mathrm{O}_{3}\right.$-HAP) to use as a support for $\mathrm{Pd}$ and these catalytic systems can be applied to catalyze the Heck reaction between iodobenzene and styrene, and the reduction of nitroarenes and nitrobenzene [22-24]. Magnetite itself is also a promising catalyst support as it was proved by the applicability of $\mathrm{Ag} / \mathrm{Fe}_{3} \mathrm{O}_{4}, \mathrm{Ag}-\mathrm{Ni} / \mathrm{Fe}_{3} \mathrm{O}_{4}, \mathrm{Pd} / \mathrm{Fe}_{3} \mathrm{O}_{4}$ and $\mathrm{Rh} / \mathrm{Fe}_{3} \mathrm{O}_{4}$ systems in the synthesis of 3,4-dihydropyrimidinones. 2,4-dihydropyrano[2,3-c]pyrazoles, and the hydrogenation of soybean oil and nitroarenes [25-28]. The two main components of the catalysts mentioned above are the support and the catalytically active metal. The catalysts are prepared through several steps, including the activation of metal, within which metal (e.g. palladium ions) ions or their complex ions are reduced to the catalytically active form (e.g. $\left.\mathrm{Pd}^{0}\right)$. In the case of $\mathrm{Pd}$ ions, the activation (reduction) can be done on the supports in aqueous solution by molecular hydrogen $\left(6 \mathrm{~atm}, 75^{\circ} \mathrm{C}\right)$ or by using $\mathrm{NaBH}_{4}$ in ethanol but the ethylene glycol is also efficient $[21,24,29]$.

In our work, a simplified reduction step was applied during the catalyst production (palladium(II) nitrate to $\mathrm{Pd}^{0}$ ) by applying alcohol and acoustic cavitation. The high energy of the ultrasonic treatment in liquids generates acoustic cavitation, which leads to the formation of micro vapor-bubbles. The collapse of the formed bubbles leads to ,hot spots" where intense local heating ( 5000 K), high pressure $(\sim 1000 \mathrm{~atm})$, enormous heating and cooling rates $(>109 \mathrm{~K} / \mathrm{s})$ and liquid jet streams $(\sim 400 \mathrm{~km} / \mathrm{h})$ appear in a small volume [30]. The energy in the „hot spots” can cover the needs of the reduction of metal ions to metals in the presence of a reducing agent [31-36]. By using of ultrasonic cavitation, palladium nanoparticles were deposited on the surface of maghemite in methanol phase. Owing to the magnetic properties of the maghemite, this is a remarkable catalyst support in liquid phase hydrogenation because the catalyst easily separated from the reaction media by magnetic field.

\section{Experiment}

\section{Materials}

Iron(III) citrate hydrate $\left(\mathrm{FeC}_{6} \mathrm{H}_{5} \mathrm{O}_{7} \cdot \mathrm{H}_{2} \mathrm{O}\right.$, PanReac AppliChem) as precursor and polyethylene glycol (PEG400, Sigma Aldrich) were applied for the synthesis of 
maghemite. Palladium(II) nitrate dihydrate $\left(\mathrm{Pd}\left(\mathrm{NO}_{3}\right)_{2} \cdot 2 \mathrm{H}_{2} \mathrm{O}\right.$, Merck) and absolute ethanol (VWR) was used to synthesize catalytically active palladium.

\section{Application of maghemite supported palladium catalyst}

Maghemite nanoparticles, as catalyst supports were synthesized by a combustion method. $3.5 \mathrm{~g}$ iron(III) citrate hydrate was dispersed in $20 \mathrm{~g}$ polyethylene glycol (PEG 400, Sigma Aldrich) by using a Hielscher Ultrasound tip homogenizer. The iron precursor containing dispersion was heated up and burned at $500{ }^{\circ} \mathrm{C}$ in a calcining furnace for two hours.

The before-synthetized maghemite was applied for catalyst preparation by using a Hielscher Ultrasound tip homogenizer (UIP1000hDT). The palladium precursor $(0.125 \mathrm{~g})$ was solved in $50 \mathrm{ml}$ abs. ethanol, and $1.00 \mathrm{~g}$ maghemite was added to the solution. The ethanolic dispersion was sonicated by using the homogenizer $(115 \mathrm{~W}$, $19.43 \mathrm{kHz}$ ) for $2 \mathrm{~min}$. Then, the catalyst was removed from the dispersion with a $\mathrm{Nd}$ magnet, washed with ethanol, and dried at $105^{\circ} \mathrm{C}$ overnight.

\section{Characterization techniques of the nanoparticles}

Maghemite and palladium nanoparticles were examined by using high-resolution transmission electron microscopy (HRTEM, FEI Technai G2 electron microscope, $200 \mathrm{kV}$ ). The samples were prepared by dropping their aqueous suspension on 300 mesh copper grids (Ted Pella Inc.). The diameters of the nanoparticles were measured on the HRTEM images, based on the original scale bar by using the ImageJ software. X-ray diffraction (XRD) measurements were used to identify and quantify the crystalline phases, by applying a Rigaku Miniflex II diffractometer with $\mathrm{Cu} \mathrm{K}_{\alpha}$ radiation source $(30 \mathrm{kV}, 15 \mathrm{~mA})$. The palladium content was determined with a Varian 720 ES inductively coupled optical emission spectrometer (ICP-OES), by using a Merck Certipur ICP multi-element standard IV.

\section{Catalytic tests}

The catalytic hydrogenation was carried out in a Büchi Uster Picoclave reactor, in a $200 \mathrm{ml}$ stainless steel vessel with heating jacket. The hydrogen pressure was $20 \mathrm{bar}$ and the reactions were carried at $283 \mathrm{~K}, 293 \mathrm{~K}$ and $323 \mathrm{~K}$. Sampling took place after the beginning of hydrogenation at 5, 10, 15, 20, 30, 60, 120, 180, and $240 \mathrm{~min}$. The initial concentration of nitrobenzene was $0.125 \mathrm{~mol} \mathrm{dm}^{-3}$ in methanol. The total amount of the solution was $150 \mathrm{ml}$ and $0.2 \mathrm{~g}$ catalyst was used during each test. Aniline formation was followed by applying Agilent 7890A gas chromatograph coupled with Agilent 5975C Mass Selective detector. Analytical standards (aniline, nitrobenzene, nitrosobenzene, azoxybenzene, dicyclohexylamine, o-toluidine, cyclohexylamine and n-methylaniline) were provided by Dr. Ehrenstorfer and Sigma Aldrich. The efficiency of the catalytic hydrogenation was compared by calculating the conversion $(\mathrm{X} \%)$ of nitrobenzene based on the following equation (Eq. 1): 


$$
X \%=\frac{\text { consumed } \boldsymbol{n}_{\text {nitrobenzene }}}{\text { initial } \boldsymbol{n}_{\text {nitrobenzene }}} \times 100 .
$$

The selectivity (S\%) of the catalyst was calculated as follows (Eq. 2):

$$
S \%=\frac{\boldsymbol{n}_{\text {aniline }}}{\boldsymbol{n}_{\text {nitrobenzene }}} \times 100
$$

re $\boldsymbol{n}_{\text {aniline }}$ and $\boldsymbol{n}_{\text {nitrobenzene }}$ are the corresponding chemical amounts of the compounds.

By assuming that the process is a first order reaction, based on the initial and measured nitrobenzene concentrations $\left(c_{0}\right.$ and $\left.c_{\mathrm{k}}, \mathrm{mol} / \mathrm{dm}^{3}\right)$, the reaction rate constant $(\mathrm{k})$ was calculated at different temperatures by non-linear regression (Fig. 4) according to the following (Eq. 3):

$$
\mathrm{c}_{k}=c_{0} * e^{-\mathrm{k} * \mathrm{t}}
$$

\section{Results and discussion}

\section{Surface morphology and phase composition of the catalyst}

The reduction of palladium ions to elemental $\mathrm{Pd}$ have been confirmed by XRD measurements (Fig. 1a). Reflections at $40^{\circ}$ and $48.8^{\circ} 2 \theta$ degrees were identified on the XRD pattern, which are attributed to the $\operatorname{Pd}(111)$ and $\operatorname{Pd}(200)$ phases (Fig. 1a, red line). Other reflections were also identified such as the peaks at $24.1^{\circ}, 30.3^{\circ}$, $35.7^{\circ}, 43.3^{\circ}, 54^{\circ}, 57.3^{\circ}$ and $63^{\circ} 2 \theta$ degrees, which are assigned to the presence of (210), (220),(100), (400), (422), (511) and (400) planes of maghemite $\left(\gamma-\mathrm{Fe}_{2} \mathrm{O}_{3}\right)$ crystalline phase. The average size of the maghemite particles was found to be $21.8 \mathrm{~nm}$ (Fig. 1b). Palladium nanoparticles were deposited onto the surface of the maghemite crystals. The palladium deposition onto the surface of the maghemite led to the aggregation of the magnetic particles, the size of the nanocomposite aggregates are between 70-200 $\mathrm{nm}$. The palladium particles on the maghemite aggregates
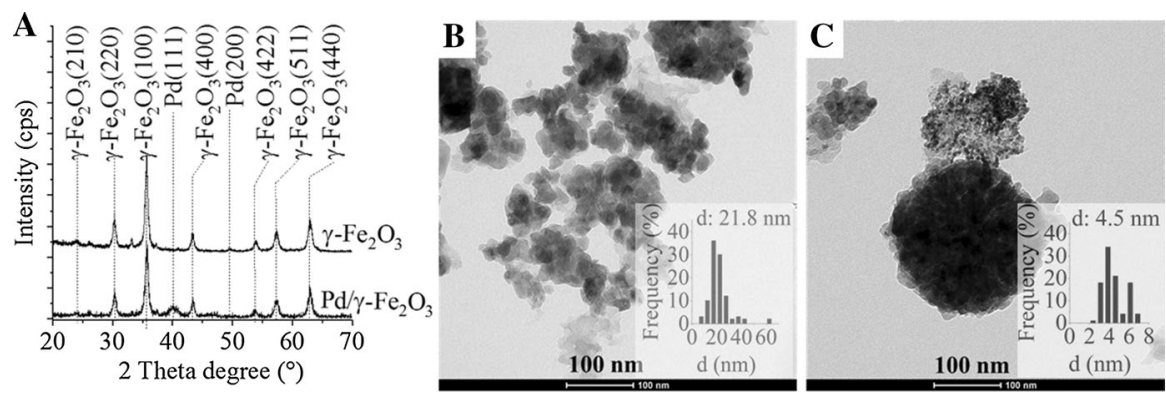

Fig. 1 XRD pattern of the maghemite (blue line) and Pd/maghemite catalyst (red line) (a) HRTEM image and size distribution of maghemite (b) and $\mathrm{Pd} /$ maghemite (c) 
are smaller than $8 \mathrm{~nm}$ (the average size is $4.5 \mathrm{~nm}$ ) (Fig. 1c). The formation of palladium nanoparticles can be explained by the reduction effect of the appearing ${ }^{-} \mathrm{H}_{2} \mathrm{R}$ radicals. These reactive species generated by the ultrasonic treatment through the reaction of $\cdot \mathrm{OH}$ radicals and ethanol $[37,38]$.

\section{Catalytic activity of the magnetic Pd catalyst}

The prepared magnetic Pd catalyst was tested in nitrobenzene hydrogenation. The maximum conversions were reached after $80 \mathrm{~min}$ at $293 \mathrm{~K}$ and $303 \mathrm{~K}$ (Fig. 2a). At $283 \mathrm{~K}$ the reaction is slower, but the total amount of nitrobenzene was transformed to aniline. The aniline selectivity was high, $97 \%$ and $96.7 \%$ at $293 \mathrm{~K}$ and $303 \mathrm{~K}$, respectively (Fig. 2b). The catalytic activity was tested through five cycles at $303 \mathrm{~K}$ and 20 bar hydrogen pressure, while the reaction time was $80 \mathrm{~min}$. The catalyst was not regenerated between the cycles, only washed with methanol. The activity started to decrease from the third cycle, which indicates that the regeneration of the catalyst is necessary (Fig. 2c).

The selectivity was lower, only $73.8 \%$, at $283 \mathrm{~K}$ which can be explained by the low reaction rate, and the persistence of the intermediates which are not converted to aniline (Fig. 3a). At $283 \mathrm{~K}$, azoxybenzene and nitrosobenzene have been detected during the reactions, which indicates that, the hydrogenation process follows the Haber mechanism [38-42]. At higher temperatures the intermediates transformed to aniline (Fig. 3b and c). The catalyst was very selective towards the formation of aniline, by-products have not been detected. All in all, the prepared maghemite supported palladium catalyst at $303 \mathrm{~K}$ reaction temperature and 20 bar hydrogen pressure can be applied effectively for aniline synthesis.

The reaction rate constants $(\mathrm{k})$ at different temperatures were calculated based on the measured nitrobenzene concentrations by using non-linear regression [43] (Fig. 4; Table 1).


Fig. 2 Conversion of nitrobenzene vs time of hydrogenation (a) and aniline selectivity (b) at various temperatures $(283,293$ and $303 \mathrm{~K})$. Aniline yield vs number of cycles at 20 bar pressure and $303 \mathrm{~K}$, after 80 min of hydrogenation 
$\nabla$ Azoxybenzene • Nitrosobenzene
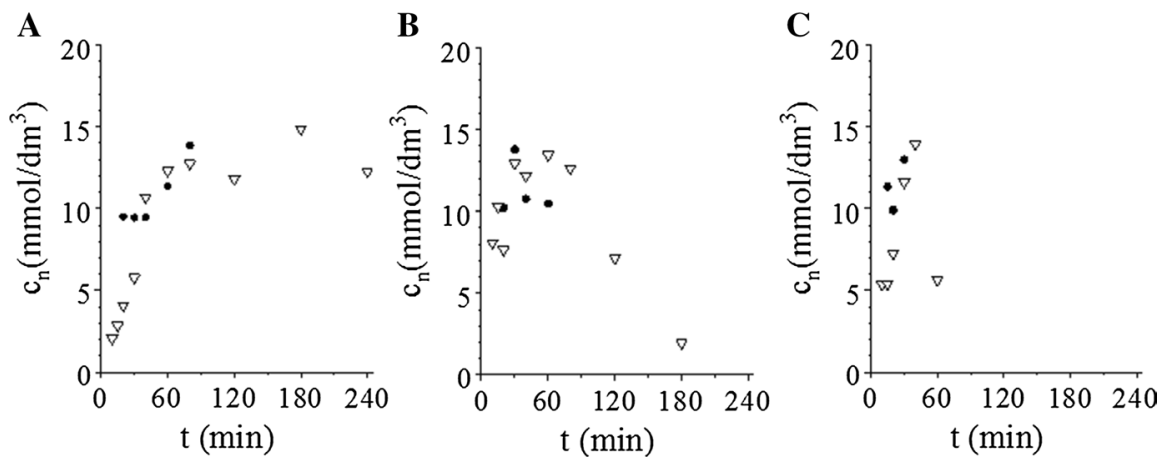

Fig. 3 Concentration of the intermediates vs time of hydrogenation, at $283 \mathrm{~K}$ (a), $293 \mathrm{~K}$ (b) and $303 \mathrm{~K}(\mathbf{c})$ at 20 bar pressure

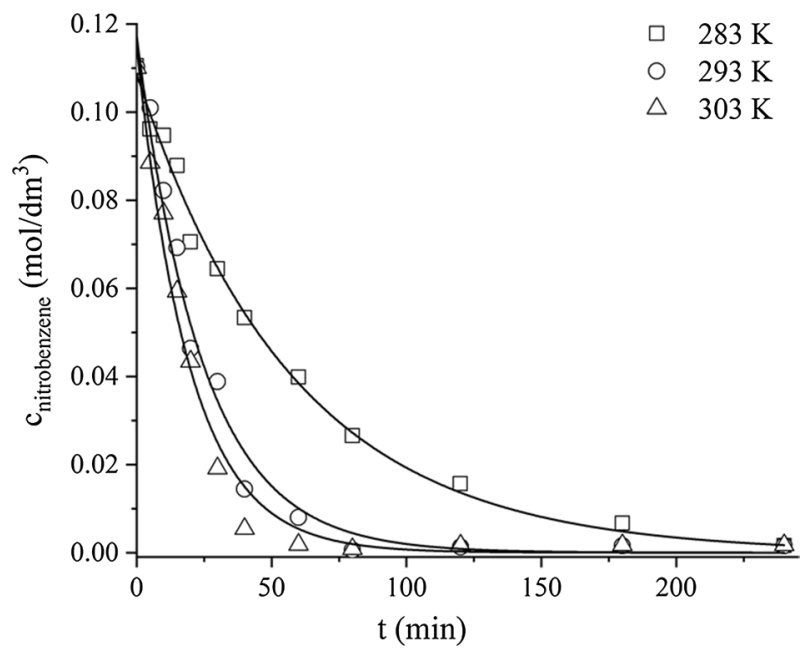

Fig. 4 Concentration of nitrobenzene vs time of hydrogenation

Table 1 Reaction rate constants of nitrobenzene hydrogenation

\begin{tabular}{llll}
\hline Temperature $(\mathrm{K})$ & 283 & 293 & 303 \\
\hline Reaction rate constant $\left(\mathrm{s}^{-1}\right)$ & $1.73 \times 10^{-2}$ & $4.09 \times 10^{-2}$ & $5.10 \times 10^{-2}$ \\
SD & $7.76 \times 10^{-4}$ & $2.99 \times 10^{-3}$ & $3.83 \times 10^{-3}$ \\
\hline
\end{tabular}

\section{Conclusion}

Maghemite supported palladium catalyst was prepared. The maghemite catalyst support was made by a newly developed combined technique, where sonochemical 
treatment and combustion have been used. This procedure leads to nanoparticles with smaller crystalline size $(21.8 \mathrm{~nm})$ and high adsorption capability. The catalyst is in an active form immediately after the production of the $\mathrm{Pd} / \mathrm{maghemite}$ nanocomposite, as the sonochemical treatment initiated the involvement of the dispersion media in the reduction of palladium ions to elemental palladium particles $\left(\mathrm{Pd}^{0}\right)$. In this sense, the catalyst does not require further post-treatments, and it does not need to be reduced under a hydrogen atmosphere, therefore the catalyst preparation method is simplified. The synthesized magnetic catalyst was efficiently applied in nitrobenzene hydrogenation at $293 \mathrm{~K}$ and $303 \mathrm{~K}$ and the conversion was more than $99 \%$ in both case. The catalyst was selective towards aniline, and the selectivity was $97.0 \%$ and $96.7 \%$ at $293 \mathrm{~K}$ and $303 \mathrm{~K}$, respectively. By-products were not detected during the reaction. All in all, a simple method has been designed for magnetic catalyst production. The achieved catalytic system is easily separable from the reaction media, thanks to its magnetic property and successfully applicable in nitrobenzene hydrogenation.

Acknowledgements Open access funding provided by University of Miskolc (ME). This research was supported by the European Union and the Hungarian State, co-financed by the European Regional Development Fund in the framework of the GINOP-2.3.4-15-2016-00004 project, aimed to promote the cooperation between the higher education and the industry. The EFOP-3.6.1-16-2016-00014 project is also gratefully acknowledged due to support our work.

\section{Compliance with ethical standards}

Conflict of interest On behalf of all authors, the corresponding author states that there is no conflict of interest.

Open Access This article is licensed under a Creative Commons Attribution 4.0 International License, which permits use, sharing, adaptation, distribution and reproduction in any medium or format, as long as you give appropriate credit to the original author(s) and the source, provide a link to the Creative Commons licence, and indicate if changes were made. The images or other third party material in this article are included in the article's Creative Commons licence, unless indicated otherwise in a credit line to the material. If material is not included in the article's Creative Commons licence and your intended use is not permitted by statutory regulation or exceeds the permitted use, you will need to obtain permission directly from the copyright holder. To view a copy of this licence, visit http://creativecommons.org/licen ses/by/4.0/.

\section{References}

1. Zhao F, Zhang R, Chatterjee M et al (2004) Hydrogenation of nitrobenzene with supported transition metal catalysts in supercritical carbon dioxide. Adv Synth Catal 346:661-668. https://doi. org/10.1002/adsc.200303230

2. Srikanth CS, Kumar VP, Viswanadham B et al (2015) Vapor phase hydrogenation of nitrobenzene to aniline over carbon supported ruthenium catalysts. J Nanosci Nanotechnol 15:5403-5409. https:// doi.org/10.1166/jnn.2015.9872

3. Zhao Y, Li C-H, Yu Z-X et al (2007) Effect of microstructures of Pt catalysts supported on carbon nanotubes (CNTs) and activated carbon (AC) for nitrobenzene hydrogenation. Mater Chem Phys 103:225-229. https://doi.org/10.1016/j.matchemphys.2007.02.045

4. Wu S, Wen G, Zhong B et al (2014) Reduction of nitrobenzene catalyzed by carbon materials. Chin J Catal 35:914-921. https://doi.org/10.1016/S1872-2067(14)60102-9 
5. Chen P, Yang F, Kostka A, Xia W (2014) Interaction of cobalt nanoparticles with oxygen- and nitrogen-functionalized carbon nanotubes and impact on nitrobenzene hydrogenation catalysis. ACS Catal 4:1478-1486. https://doi.org/10.1021/cs500173t

6. Collins DJ, Smith AD, Davis BH (1982) Hydrogenation of nitrobenzene over a nickel boride catalyst. Ind Eng Chem Prod Res Dev 21:279-281. https://doi.org/10.1021/i300006a016

7. Hatziantoniou V, Andersson B, Schoon NH (1986) Mass transfer and selectivity in liquid-phase hydrogenation of nitro compounds in a monolithic catalyst reactor with segmented gas-liquid flow. Ind Eng Chem Process Des Dev 25:964-970. https://doi.org/10.1021/i200035a021

8. Liao H-G, Xiao Y-J, Zhang H-K et al (2012) Hydrogenation of nitrocyclohexane to cyclohexanone oxime over Pd/CNT catalyst under mild conditions. Catal Commun 19:80-84. https://doi. org/10.1016/J.CATCOM.2011.12.027

9. Li C-H, Yu Z-X, Yao K-F et al (2005) Nitrobenzene hydrogenation with carbon nanotube-supported platinum catalyst under mild conditions. J Mol Catal A 226:101-105. https://doi.org/10.1016/j. molcata.2004.09.046

10. Dong B, Li Y, Ning X et al (2017) Trace iron impurities deactivate palladium supported on nitrogen-doped carbon nanotubes for nitrobenzene hydrogenation. Appl Catal A 545:54-63. https://doi. org/10.1016/j.apcata.2017.07.035

11. Hao L, Li H, Hu Y et al (2014) Carbon nanotube-supported bimetallic Pt-Fe catalysts for nitrobenzene hydrogenation. Micro Nano Lett 9:97-99. https://doi.org/10.1049/mnl.2013.0624

12. Zhao F, Ikushima Y, Arai M (2004) Hydrogenation of nitrobenzene with supported platinum catalysts in supercritical carbon dioxide: effects of pressure, solvent, and metal particle size. J Catal 224:479-483. https://doi.org/10.1016/j.jcat.2004.01.003

13. Kim Y, Ma R, Reddy DA, Kim TK (2015) Liquid-phase pulsed laser ablation synthesis of graphitized carbon-encapsulated palladium core-shell nanospheres for catalytic reduction of nitrobenzene to aniline. Appl Surf Sci 357:2112-2120. https://doi.org/10.1016/J.APSUSC.2015.09.193

14. dos Santos-Durndell VC, Peruzzolo TM, Ucoski GM et al (2018) Magnetically recyclable nanocatalysts based on magnetite: an environmentally friendly and recyclable catalyst for esterification reactions. Biofuel Res J 5:806-812. https://doi.org/10.18331/BRJ2018.5.2.4

15. Nasrollahzadeh M, Issaabadi Z, Safari R (2019) Synthesis, characterization and application of $\mathrm{Fe}_{3} \mathrm{O}_{4} @ \mathrm{SiO}_{2}$ nanoparticles supported palladium(II) complex as a magnetically catalyst for the reduction of 2,4-dinitrophenylhydrazine, 4-nitrophenol and chromium(VI): a combined theoretical (DFT) and experimental study. Sep Purif Technol 209:136-144. https://doi.org/10.1016/j.seppu r.2018.07.022

16. Yavari I, Mobaraki A, Hosseinzadeh Z, Sakhaee N (2019) Copper-catalyzed Mizoroki-Heck coupling reaction using an efficient and magnetically reusable $\mathrm{Fe}_{3} \mathrm{O}_{4} @ \mathrm{SiO}_{2} @ \mathrm{PrNCu}$ catalyst. J Organomet Chem 897:236-246. https://doi.org/10.1016/J.JORGANCHEM.2019.06.029

17. Wang J, Lou Y, Zhuang X et al (2018) Magnetic Pr6O11/ $/ \mathrm{SiO}_{2} @ \mathrm{Fe}_{3} \mathrm{O}_{4}$ particles as the heterogeneous catalyst for the catalytic ozonation of acetochlor: Performance and aquatic toxicity. Sep Purif Technol 197:63-69. https://doi.org/10.1016/j.seppur.2017.12.052

18. Desmecht A, Pennetreau F, L'hoost A et al (2019) Preparation of magnetically recoverable carbon nanotube-supported Pd(II) catalyst. Catal Today 334:24-29. https://doi.org/10.1016/j.catto d.2019.02.057

19. Mei N, Liu B (2016) Pd nanoparticles supported on $\mathrm{Fe}_{3} \mathrm{O}_{4} @ \mathrm{C}$ : an effective heterogeneous catalyst for the transfer hydrogenation of nitro compounds into amines. Int J Hydrogen Energy 41:1796017966. https://doi.org/10.1016/j.ijhydene.2016.07.229

20. Rahimi E, Sajednia G, Baghdadi M, Karbassi A (2018) Catalytic chemical reduction of nitrate from simulated groundwater using hydrogen radical produced on the surface of palladium catalyst supported on the magnetic alumina nanoparticles. J Environ Chem Eng 6:5249-5258. https://doi. org/10.1016/j.jece.2018.08.026

21. Gil J, Ferreira LF, Silva VC et al (2019) Facile fabrication of functionalized core-shell $\mathrm{Fe}_{3} \mathrm{O}_{4} @$ $\mathrm{SiO}_{2} @ \mathrm{Pd}$ microspheres by urea-assisted hydrothermal route and their application in the reduction of nitro compounds. Environ Nanotechnol Monit Manag 11:100220. https://doi.org/10.1016/j. enmm.2019.100220

22. Wang G, Ling Y, Wheeler DA et al (2011) Facile synthesis of highly photoactive $\alpha$-Fe2O 3-based films for water oxidation. Nano Lett 11:3503-3509. https://doi.org/10.1021/nl202316j

23. Ghonchepour E, Islami MR, Bananezhad B et al (2019) Synthesis of recoverable palladium composite as an efficient catalyst for the reduction of nitroarene compounds and Suzuki cross-coupling 
reactions using sepiolite clay and magnetic nanoparticles $\left(\mathrm{Fe}_{3} \mathrm{O}_{4} @\right.$ sepiolite- $\left.\mathrm{Pd}^{2+}\right)$. Comptes Rendus Chim 22:84-95. https://doi.org/10.1016/j.crci.2018.07.008

24. Jiang L, Zhang Z (2016) Efficient transfer hydrogenation of nitro compounds over a magnetic palladium catalyst. Int $\mathrm{J}$ Hydrogen Energy 41:22983-22990. https://doi.org/10.1016/j.ijhyd ene.2016.09.182

25. Mirhashemi F, Ali Amrollahi M (2019) Decoration of $\beta$-CD on $\mathrm{Fe}_{3} \mathrm{O}_{4} @ \mathrm{Ag}$ core-shell nanoparticles as a new magnetically recoverable and reusable catalyst for the synthesis of 3,4-dihydropyrimidinones and 2,4-dihydropyrano[2,3-c]pyrazoles in $\mathrm{H}_{2} \mathrm{O}$. Inorganica Chim Acta 486:568-575. https:// doi.org/10.1016/j.ica.2018.11.009

26. Wang L, Wang W, Wang $\mathrm{Y}$ et al (2018) Structural characteristics of a Ni-Ag magnetic catalyst and its properties in soybean oil hydrogenation. Food Bioprod Process 109:139-147. https://doi. org/10.1016/j.fbp.2018.03.008

27. Kandathil V, Koley TS, Manjunatha $\mathrm{K}$ et al (2018) A new magnetically recyclable heterogeneous palladium(II) as a green catalyst for Suzuki-Miyaura cross-coupling and reduction of nitroarenes in aqueous medium at room temperature. Inorganica Chim Acta 478:195-210. https://doi. org/10.1016/j.ica.2018.04.015

28. Shaikh MN, Helal A, Kalanthoden AN et al (2019) Sub-nanometric Rh decorated magnetic nanoparticles as reusable catalysts for nitroarene reduction in water. Catal Commun 119:134-138. https ://doi.org/10.1016/j.catcom.2018.09.002

29. Park J, Bae S (2019) Highly efficient and magnetically recyclable Pd catalyst supported by iron-rich fly ash@fly ash-derived $\mathrm{SiO}_{2}$ for reduction of p-nitrophenol. J Hazard Mater 371:72-82. https://doi. org/10.1016/j.jhazmat.2019.02.105

30. Suslick KS (2000) Sonochemistry. In: Suslick KS (ed) Kirk-Othmer encyclopedia of chemical technology. Wiley, Hoboken.

31. Qiu X-F, Zhu J-J (2003) Synthesis of palladium nanoparticles by a sonochemical method. Chinese J Inorg Chem 19:766-770

32. Yu Y, Zhang QY, Li XG (2003) Reduction process of transition metal ions by zinc powder to prepare transition metal nanopowder. Acta Phys Chim Sin 19:436-440. https://doi.org/10.3866/PKU. WHXB20030512

33. Qiu X-F, Zhu J-J, Chen H-Y (2003) Controllable synthesis of nanocrystalline gold assembled whiskery structures via sonochemical route. J Cryst Growth 257:378-383. https://doi.org/10.1016/S0022 $-0248(03) 01467-2$

34. Wu S-H, Chen D-H (2003) Synthesis and characterization of nickel nanoparticles by hydrazine reduction in ethylene glycol. J Colloid Interface Sci 259:282-286. https://doi.org/10.1016/S0021 -9797(02)00135-2

35. Kan C, Cai W, Li C et al (2003) Ultrasonic synthesis and optical properties of Au/Pd bimetallic nanoparticles in ethylene glycol. J Phys D 36:1609-1614. https://doi.org/10.1088/0022-3727/36/13/328

36. Li Q, Li H, Pol VG et al (2003) Sonochemical synthesis, structural and magnetic properties of airstable Fe/Co alloy nanoparticles. New J Chem 27:1194. https://doi.org/10.1039/b302136j

37. Okitsu K, Bandow H, Maeda Y, Nagata Y (1996) Sonochemical preparation of ultrafine palladium particles. Chem Mater 8:315-317. https://doi.org/10.1021/cm950285s

38. Turáková M, Salmi T, Eränen K et al (2015) Liquid phase hydrogenation of nitrobenzene. Appl Catal A 499:66-76. https://doi.org/10.1016/j.apcata.2015.04.002

39. Leipzig B (1898) Über stufenweise Reduktion des Nitrobenzols mit begrenztem Kathodenpotential. Z Elektrotech Elektrochem 4:506-514. https://doi.org/10.1002/bbpc.18980042204

40. Qu R, Macino M, Iqbal S et al (2018) Supported bimetallic AuPd nanoparticles as a catalyst for the selective hydrogenation of nitroarenes. Nanomaterials 8:690. https://doi.org/10.3390/nano8090690

41. Peureux J, Torres M, Mozzanega $\mathrm{H}$ et al (1995) Nitrobenzene liquid-phase hydrogenation in a membrane reactor. Catal Today 25:409-415. https://doi.org/10.1016/0920-5861(95)00128-3

42. Easterday R, Sanchez-Felix O, Losovyj Y et al (2015) Design of ruthenium/iron oxide nanoparticle mixtures for hydrogenation of nitrobenzene. Catal Sci Technol 5:1902-1910. https://doi. org/10.1039/C4CY01277A

43. Lente G (2015) Deterministic kinetics in chemistry and systems biology. Springer, Cham

Publisher's Note Springer Nature remains neutral with regard to jurisdictional claims in published maps and institutional affiliations. 


\section{Affiliations}

Viktória Hajdu ${ }^{1}$. Ádám Prekob ${ }^{1}$. Gábor Muránszky ${ }^{1}$. István Kocserha ${ }^{2}$. Zoltán Kónya $^{3}$ · Béla Fiser ${ }^{1,4}$ • Béla Viskolcz ${ }^{1}$ László Vanyorek ${ }^{1}$

Viktória Hajdu

kemviki@uni-miskolc.hu

Ádám Prekob

kempadam@uni-miskolc.hu

Gábor Muránszky

kemmug@uni-miskolc.hu

István Kocserha

istvan.kocserha@uni-miskolc.hu

Zoltán Kónya

konya@chem.u-szeged.hu

Béla Fiser

kemfiser@uni-miskolc.hu

Béla Viskolcz

bela.viskolcz@uni-miskolc.hu

1 Institute of Chemistry, University of Miskolc, 3515 Miskolc-Egyetemváros, Hungary

2 Institute of Cermics and Polymer Engineering, University of Miskolc, 3515 Miskolc-Egyetemváros, Hungary

3 Department of Applied and Environmental Chemistry, University of Szeged, Rerrich Béla sq. 1, 6720 Szeged, Hungary

4 Ferenc Rákóczi II. Transcarpathian Hungarian Institute, Beregszász, Transcarpathia 90200, Ukraine 